\title{
Time-domain seismic reliability of nonlinear structures
}

\author{
ACHINTYA HALDAR ${ }^{1}$, JUNGWON HUH ${ }^{2}$ and ALI MEHRABIAN ${ }^{3}$ \\ ${ }^{1}$ University of Arizona, Tucson, AZ 85721, U.S.A. \\ ${ }^{2}$ Chonnam National University, Yeosu, 550-749, Republic of Korea \\ ${ }^{3}$ University of Central Florida, Orlando, FL 32816, U.S.A. \\ e-mail: haldar@u.arizona.edu; jwonhuh@chonnam.ac.kr; mehrabia@mail.ucf.edu
}

\begin{abstract}
A novel reliability analysis technique is presented to estimate the reliability of real structural systems. Its unique feature is that the dynamic loadings can be applied in time domain. It is a nonlinear stochastic finite element logarithm combined with the response surface method (RSM). It generates the response surface around the most probable failure point and incorporates information of the distribution of the random variables in the RSM formulation. It is verified using the Monte Carlo simulation technique, and is found to be very efficient and accurate. Most sources of nonlinearlity and uncertainty can be explicitly incorporated in the formulation. The flexibility of connections, represented by moment-relative rotation $(M-\theta)$ curves, is addressed. After the Northridge earthquake of 1994, several improved steel connections were proposed. Structural Sesimic Design Associates (SSDA) tested several full-scale proprietory slotted web beam-column connections. The authors suggested $(M-\theta)$ curves for this connection using actual test data. Behaviours of steel frames, assuming the connections are fully restrained, partially restrained, consisting of pre- and post-Northridge connections are evaluated and compared. Desirable features of the post-Northridge connections observed during testing are analytically confirmed. Laterally weak steel frame is then strengthened with concrete shear walls. Capabilities and the advanced nature of the method are demonstrated with the help of realistic examples.
\end{abstract}

Keywords. Reliability analysis; seismic analysis; nonlinear response, partially restrained connections, shear walls; post-Northridge connections.

\section{Introduction}

It is well accepted in the profession that engineering analysis, design, and decisions are often made in the presence of incomplete information or uncertainty. A conventional safety factor format is routinely used to address the presence of uncertainty. Reliability-based design codes have already been developed or are being developed to replace the safety factor concept and the deterministic community has accepted this new trend. However, the major concern

This paper is dedicated to Prof R N Iyengar of the Indian Institute of Science on the occasion of his formal retirement. 
is that the available reliability evaluation techniques are very limited in scope. They can evaluate risk for idealized structures mostly at the element level. They are unable to estimate the risk of structures at the system level considering their realistic, including nonlinear, behaviour.

\section{Stochastic finite element method - Static problems}

To address this concern, comprehensive multidisciplinary efforts were made to improve the state-of-the-art in the reliability evaluation of real structures over the last three decades. Finite element analysis is a very powerful tool commonly used by many engineering disciplines to analyse both simple and complicated structures. With this approach, it is straightforward to consider complicated geometric arrangements, constitutive relationships of the material, realistic connection and support conditions, and the load path to failure. It gives acceptable results for known or assumed values of all the variables in the formulation while ignoring the uncertainty in them. In early eighties, the first author started developing a reliability analysis technique using the finite element method leading to the concept of the stochastic finite element method (SFEM) (see Haldar \& Mahadevan 2000b). The acronym SFEM has been used by other researchers, however, in different contexts. With the advances in computer technology, it is appropriate to develop a finite element-based relaibility analysis technique, parallel to the deterministic analysis procedure, for wider acceptance and applications.

Reliability is always estimated with respect to performance or limit state functions. They are functions of all load and resistance-related variables and the allowable or permissible values for a particular design. They could be implicit or explicit in nature. The SFEM approach can be used for both cases. If the limit state function $g(\mathbf{x})$ is an explicit function of all the variables $\mathbf{x}$, generally the first-order reliability method (FORM) is used since it is easy to compute the derivatives of $g(\mathbf{x})$ with respect to the random variables $\mathbf{x}$ in order to proceed with the search for the minimum distance point on the limit state (Haldar \& Mahadevan 2000a). However, for realistic structures, $g(\mathbf{x})$ is expected to be implicit in most cases and the classical FORM will be inapplicable. Several computational approaches can be pursued for the reliability analysis of structures with implicit limit state functions. For the purpose of discussion, they can be broadly divided into three categories, namely (1) Monte Carlo simulation, (2) response surface approach, and (3) sensitivity-based analysis. The basic Monte Carlo simulation scheme could be simple to apply but could be inefficient, time-consuming, and impractical if the structure is represented with numerous finite elements and the deterministic solutions take a lot of time. The response surface approach approximately constructs the limit state function with the help of a few selected deterministic analyses. However, its applicability could be limited if the region where the limit state function needs to be generated is not known. In the sensitivitybased approach, the sensitivity of the structural response to the input variables is computed and it can be integrated with the FORM approach to extract the information on the underlying reliability. The value of the performance function is evaluated using deterministic structural analysis. The gradient is computed using sensitivity analysis. When the limit state function is implicit, the sensitivities can be computed in three different ways: (1) through a finite difference approach, (2) through classical perturbation methods that apply the chain rule of differentiation to finite element analysis, and (3) through iterative perturbation analysis techniques (Haldar \& Mahadevan 2000b). The sensitivity-based reliability analysis approach is more elegant and, in general, more efficient than the simulation or response surface methods. 
Haldar \& Mahadevan (2000b) suggested the use of the iterative perturbation technique in the context of the basic nonlinear SFEM-based algorithm.

\subsection{Unified stochastic finite element method}

Without losing any generality, the limit state function can be expressed in terms of the set of basic random variables $\mathbf{x}$ (e.g., loads, material properties and structural geometry), the set of displacements $\mathbf{u}$ and the set of load effects $\mathbf{s}$ (except the displacements, such as internal forces). The displacement $\mathbf{u}=\mathbf{Q D}$, where $\mathbf{D}$ is the global displacement vector and $\mathbf{Q}$ is a transformation matrix. The limit state function can be expressed as $g(\mathbf{x}, \mathbf{u}, \mathbf{s})=0$. For reliability computation, it is convenient to transform $\mathbf{x}$ into the standard normal space $\mathbf{y}=$ $y(\mathbf{x})$ such that the elements of $\mathbf{y}$ are statistically independent and have a standard normal distribution. An iteration algorithm can be used to locate the design point (the most likely failure point) on the limit state function using first-order approximation. During each iteration, the structural response and the response gradient vectors are calculated using finite element models. The following iteration scheme can be used for finding the coordinates of the design point:

$$
\mathbf{y}_{i+1}=\left[\mathbf{y}_{i}^{t} \alpha_{i}+\frac{g\left(\mathbf{y}_{i}\right)}{\left|\nabla g\left(\mathbf{y}_{i}\right)\right|}\right] \alpha_{i}
$$

where

$$
\nabla g(\mathbf{y})=\left[\frac{\partial g(\mathbf{y})}{\partial y_{1}}, \ldots, \frac{\partial g(\mathbf{y})}{\partial y_{n}}\right]^{t} \text { and } \alpha_{i}=-\frac{\nabla g\left(\mathbf{y}_{i}\right)}{\left|\nabla g\left(\mathbf{y}_{i}\right)\right|} .
$$

To implement the algorithm, the gradient $\nabla g(\mathbf{y})$ of the limit state function in the standard normal space can be derived as (Haldar \& Mahadevan 2000b):

$$
\nabla g(\mathbf{y})=\left[\frac{\partial g(\mathbf{y})}{\partial \mathbf{s}} \mathbf{J}_{s, x}+\left(\mathbf{Q} \frac{\partial g(\mathbf{y})}{\partial \mathbf{u}}+\frac{\partial g(\mathbf{y})}{\partial \mathbf{s}} \mathbf{J}_{s, D}\right) \mathbf{J}_{D, x}+\frac{\partial g(\mathbf{y})}{\partial \mathbf{x}}\right] \mathbf{J}_{y, x}^{-1},
$$

where $\mathbf{J}_{i, j}$ 's are the Jacobians of transformation (e.g., $\mathbf{J}_{s, x}=\partial \mathbf{s} / \partial \mathbf{x}$ ) and $y_{i}$ 's are statistically independent random variables in the standard normal space. The evaluation of the quantities in (3) will depend on the problem under consideration (linear or nonlinear, two- or threedimensional etc.) and the performance functions used. The essential numerical aspect of SFEM is the evaluation of three partial derivatives, $\partial g / \partial \mathbf{s}, \partial g / \partial \mathbf{u}$, and $\partial g / \partial \mathbf{x}$, and four Jacobians, $\mathbf{J}_{s, x}, \mathbf{J}_{s, D}, \mathbf{J}_{D, x}$, and $\mathbf{J}_{y, x}$. They can be evaluated by procedures suggested by Haldar \& Mahadevan (2000b). Once the coordinates of the design point $\mathbf{y}^{*}$ are evaluated with a preselected convergence criterion, the reliability index $\beta$ can be evaluated as:

$$
\beta=\left[\left(\mathbf{y}^{*}\right)^{t}\left(\mathbf{y}^{*}\right)\right]^{1 / 2} .
$$

The probability of failure, $P_{f}$, can be calculated as:

$$
P_{f}=\Phi(-\beta)=1 \cdot 0-\Phi(\beta),
$$

where $\Phi$ is the standard normal cumulative distribution function. Equation (5) can be considered as a notational failure probability. When the reliability index is larger, the probability of failure will be smaller. 


\subsection{Limit state functions}

Both strength and serviceability limits states are necessary to study the underlying risk of a system. For the ease of comprehension, some of the commonly used limit states are discussed next.

2.2a Strength limit state function: According to the American Institute of Steel Construction's (AISC's) load and resistance factor design (LRFD) guidelines (AISC 2001), the strength limit state function for two-dimensional steel frame members can be defined as:

$$
g(\mathbf{x}, \mathbf{u}, \mathbf{s})=1.0-\frac{P_{u}}{P_{n}}-\frac{8}{9}\left(\frac{M_{u x}}{M_{n x}}\right) ; \quad \text { if } \frac{P_{u}}{\phi P_{n}} \geq 0.2,
$$

or

$$
g(\mathbf{x}, \mathbf{u}, \mathbf{s})=1 \cdot 0-\left(\frac{P_{u}}{2 P_{n}}+\frac{M_{u x}}{M_{n x}}\right) ; \quad \text { if } \frac{P_{u}}{\phi P_{n}}<0 \cdot 2,
$$

where $P_{u}$ is the required tensile and compressive strength, $P_{n}$ is the nominal tensile and compressive strength, $M_{u x}$ is the required flexural strength, and $M_{n x}$ is the nominal flexural strength. $P_{u}$ and $M_{u x}$ in (6) and (7) are unfactored load effects. Nominal axial load and bending moment capacity of a steel member can be calculated using the procedures suggested in AISC's LRFD design guidelines (AISC 2001).

2.2b Serviceability limit state function: Vertical deflection at the midspan of beams and the lateral displacements at the top of the frame can be considered to be the two serviceability performance functions for a typical frame. For the serviceability criterion, the limit state function is generally represented as:

$$
g(\mathbf{x}, \mathbf{u}, \mathbf{s})=1 \cdot 0-\left(\delta / \delta_{\text {limit }}\right),
$$

where $\delta$ is the calculated displacement component and $\delta_{\text {limit }}$ is the prescribed maximum value of the displacement component. The allowable or the prescribed maximum value of the displacement component is generally suggested in design guidelines.

SFEM-based reliability analysis of real nonlinear structures under static loading conditions has been discussed extensively in the literature (Mahadevan \& Haldar 1991; Haldar \& Zhou 1992; Gao \& Haldar 1995a; Lee \& Haldar 2003a) and accepted by the profession. For the sake of brevity, it will not be discussed further here.

\section{Seismic reliability of nonlinear structures}

The extension of the static nonlinear SFEM-based approach to evaluate the nonlinear dynamic or seismic reliability of nonlinear structures is expected to be challenging. A time-domain finite-element based-approach considering all major sources of nonlinearity and uncertainty will be appealing to most engineering communities and is discussed next.

\subsection{Sources of nonlinearity}

Sesimic reliability of steel frame structures is emphasized in this paper. The sources of nonlinearity in steel structures need to be understood properly to help incorporate them in the 
algorithm. Since steel frames are made of slender members and ends are connected differently than frames made of concrete, additional sources of nonlinearities, besides geometric and material, are expected to be present. Nonlinear behaviour due to changes in the geometry of the frames is generally referred as the geometric nonlinearity. The effects of geometric nonlinearity give rise to the secondary moments, which are caused by the axial force acting either through the lateral displacement of the member relative to the chord $(P-\delta)$ or through the relative lateral displacement of the two ends of the member $(P-\Delta)$, and the finite rigid body deformation with small to moderate rotation of a member. Material nonlinearity arises when yielding occurs or if the stress-strain behaviour exhibits a nonlinear constitutive relationship. The state of the art in considering geometric and material nonlinearities are very advanced (Haldar \& Nee 1989; Haldar \& Mahadevan 2000b) and does not need any additional discussion here.

\subsection{Flexibility of connections}

The flexibility of connections or supports in steel frames is another major source of nonlinearity. However, they are generally considered to be fully restrained (FR) and are overlooked in numerical analyses. Severe damages in steel connections during the Northridge earthquake of 1994 indicated the deficiency or limitation in our current understanding of evaluating the behaviour of steel frames. Connections in steel frames are essentially of partially restrained (PR) type with different flexibilities. The implication is that the classical numerical analysis procedure routinely used to analyse a frame is inapplicable. Furthermore, PR connections not only change the dynamic properties, e.g., the natural frequencies, stiffness, damping etc., in the dynamic analyses, but also reduce the overall stiffness of frames and add a major sources of energy dissipation, a type of hysteretic damping. The loading, unloading, and reloading behaviour of PR connections and the uncertainty associated in modelling them must be appropriately considered in the reliability evaluation of steel frames. Modelling of realistic behaviour of connections in steel frames is very complicated and is often overlooked by the profession.

The flexibility in the connections can be represented by a relationship between the moment $M$, transmitted by the connection, and the relative rotation angle $\theta$. The relationship is generally represented by $M-\theta$ curves. Several mathematical models are available in the literature for this purpose (Reyes \& Haldar 2001). Due to its many advantages over other available models, the Richard four-parameter moment-rotation model (Richard \& Abbott 1975) is chosen here to represent the flexible behaviour as shown in figure 1 . The loading segment of the relationship can be expressed as:

$$
M=\left\{\left(k-k_{p}\right) \theta /\left(1+\left|\left(k-k_{p}\right) \theta / M_{0}\right|^{N}\right)^{1 / N}\right\}+k_{p} \theta,
$$

where $M$ is the moment, $\theta$ the relative rotation between the connecting elements, $k$ the initial stiffness, $k_{p}$ the plastic stiffness, $M_{0}$ the reference moment, and $N$ the curve shape parameter. Procedures to evaluate these parameters for a typical $M-\theta$ curve are discussed by Mehrabian (2002).

Equation (9) represents only the monotonically increasing loading portion of the $M-\theta$ curves. For seismic analysis, the unloading and reloading parts of the $M-\theta$ curves must be available. However, the required information is unavailable in most cases. Colson (1991) proposed a method to develop unloading and reloading behaviours theoretically using the Masing rule (Gao \& Haldar 1995b; Reyes \& Haldar 2001). The unloading and reloading 


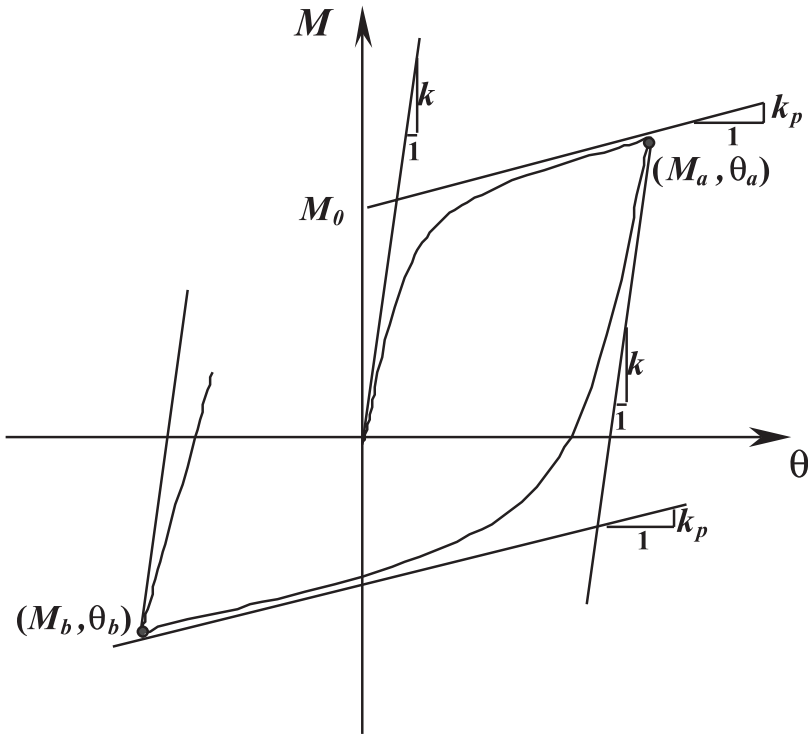

Figure 1. Loading, unloading, and reverse loading model of PR connections.

relationships of a PR connection, used in this study, can be represented as:

$$
\begin{aligned}
M= & M_{a}-\left\{\left(k-k_{p}\right)\left(\theta_{a}-\theta\right) /\left(1+\left|\left(k-k_{p}\right)\left(\theta_{a}-\theta\right) / 2 M_{0}\right|^{N}\right)^{1 / N}\right\} \\
& -k_{p}\left(\theta_{a}-\theta\right) .
\end{aligned}
$$

If $\left(M_{b}, \theta_{b}\right)$ in figure 1 is the next load-reversal point, the reloading relationship between $M$ and $\theta$ can be obtained by simply replacing $\left(M_{a}, \theta_{a}\right)$ with $\left(M_{b}, \theta_{b}\right)$ in (10). Therefore, the proposed method uses (9) when the connection is loading and (10) when the connection is unloading and reloading. This represents hysteretic behaviour of the PR connections.

The assumed stress-based FEM approach used in this study uses a beam-column element to model both regular structural elements and flexible connections. One element is added for each PR connection. However, the stiffness of PR connections needs to be updated at every iteration since it depends on $\theta$. This can be accomplished by updating Young's modulus as:

$$
E_{C}(\theta)=\left(l_{C} / I_{C}\right) K_{C}(\theta)=\left(l_{C} / I_{C}\right)[\partial M(\theta) / \partial \theta],
$$

where $l_{C}, I_{C}$, and $K_{C}(\theta)$ are the length, the moment of inertia, and the tangent stiffness of the connection element respectively. When the element is loading, using $(9), K_{C}(\theta)$ is evaluated as:

$$
K_{C}(\theta)=\mathrm{d} M / \mathrm{d} \theta=\left\{\left(k-k_{p}\right) /\left(1+\left|\left(k-k_{p}\right) \theta / M_{0}\right|^{N}\right)^{(N+1) / N}\right\}+k_{p} .
$$

When the element is unloading and reloading, using $(10), K_{C}(\theta)$ can be calculated as:

$$
K_{C}(\theta)=\mathrm{d} M / \mathrm{d} \theta=\left\{\left(k-k_{p}\right) /\left(1+\left|\left(k-k_{p}\right)\left(\theta_{a}-\theta\right) /\left(2 M_{0}\right)\right|^{N}\right)^{(N+1) / N}\right\}+k_{p} .
$$

The basic FEM formulation of the structure remains unchanged, except for adding a few more elements to represent PR connections. 


\subsection{Post-Northridge PR connections}

One of the typically damaged steel beam-column connections during the Northridge earthquake of 1994 was a bolted-web, welded-flange (BWWF) connection. As conceptually illustrated in figure 2, BWWF connections were fabricated with the beam flanges attached to the column flanges by full penetration welds (field-welded) and with the beam web bolted (fieldbolted) to single plate shear tabs (Richard \& Radau 1998). BWWF connections are generally referred to as "pre-Northridge" connections. BWWF connections were commonly used in the construction of steel moment resisting frames (SMRFs) prior to the Northridge earthquake of 1994. However, as mentioned earlier, many of them fractured in a brittle and premature manner during the earthquake. Following the Northridge earthquake, Structural Engineering Association of California (SEAOC) recommended that use of BWWF connections be stopped.

The post-Northridge steel connection research emphasized on identifying the causes of the damage, and developing new steel beam-column connections that could improve the overall response, ductility and the quality of future designs. In the post-Northridge design practices of steel connections, the thrusts are on making the connections more flexible than the preNorthridge connections and moving the location of formation of any plastic hinge away from the connection. Providing more ductility to increase the energy absorption capacity of the connection during an earthquake is another major objective in the design. Several improved connections can be found in the literature including cover-plated connections (Engelhardt \& Sabol 1995), spliced beam connections, side-plated connections, bottom haunch connections, connections with vertical ribs, and connections with reduced beam sections (RBS) or

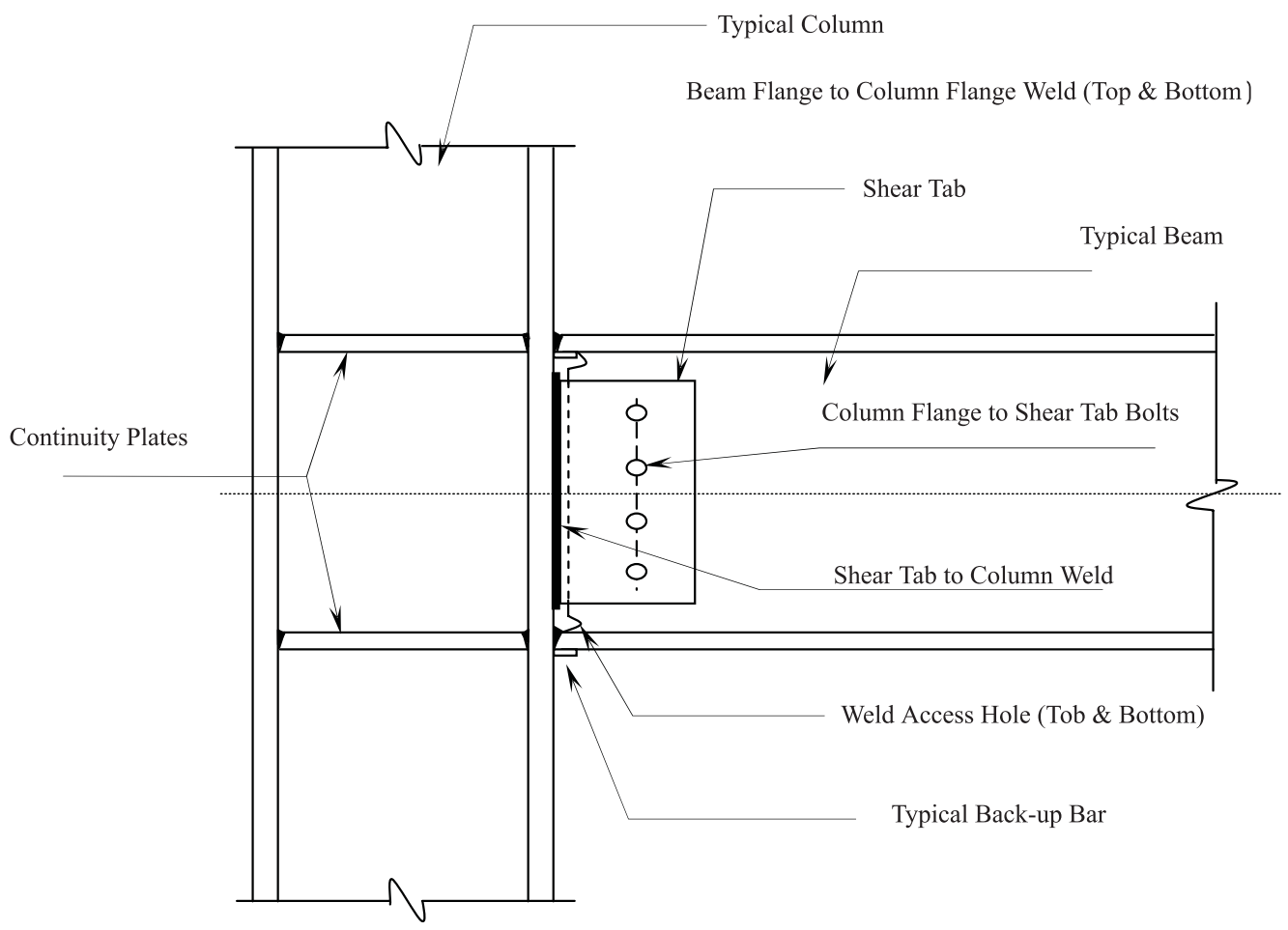

Figure 2. Pre-Northridge BWWF connection detail. 


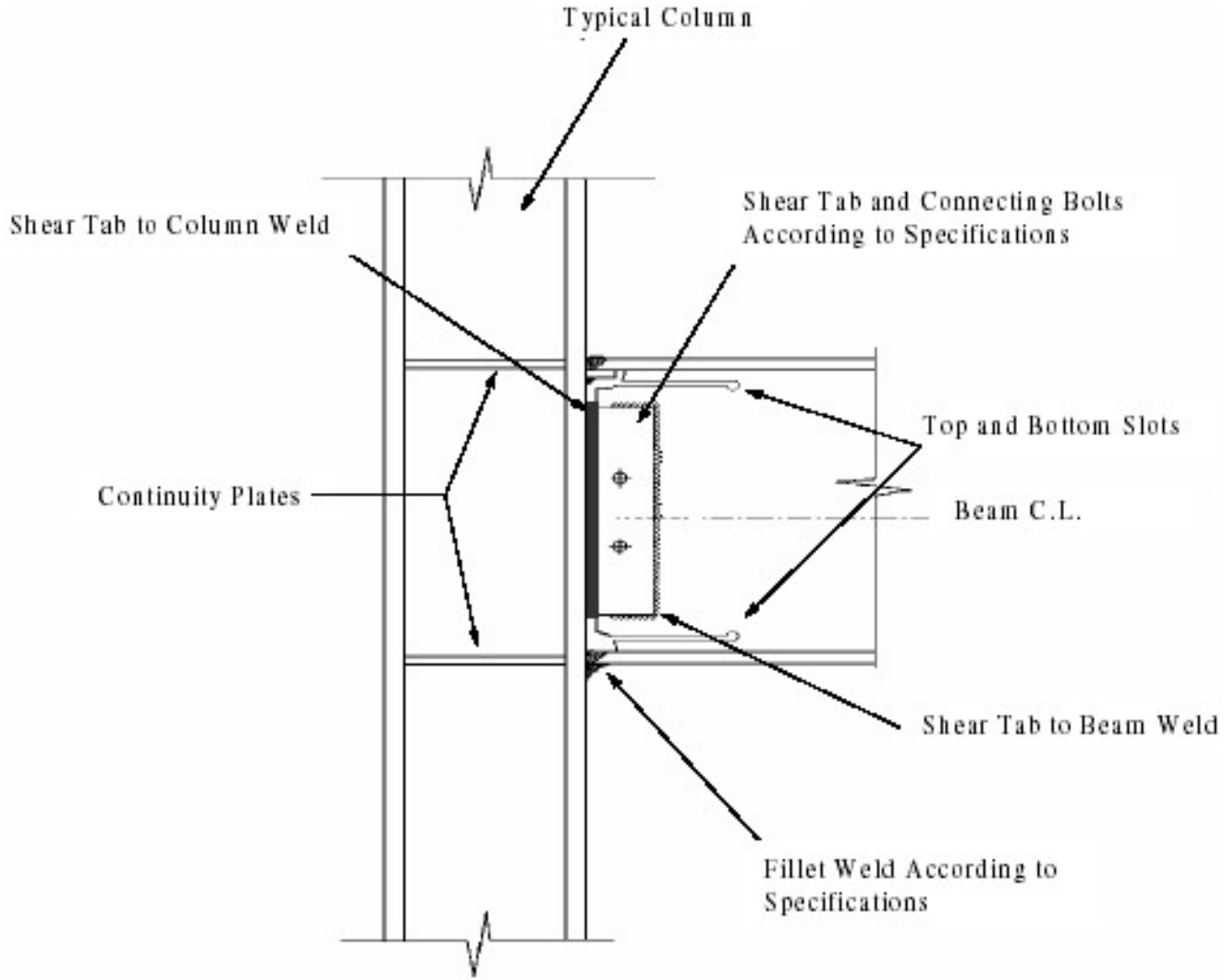

Figure 3. Post-Northridge BWWF-AD (SlottedWeb ${ }^{\mathrm{TM}}$ ) connection detail.

dog-boned sections (FEMA 2000). Other forms of "post-Northridge" connections are also available in the literature (FEMA 2000).

Seismic Structural Design Associates, Inc. (SSDA) proposed a unique proprietary slotted web (SSDA SlottedWeb ${ }^{\mathrm{TM}}$ ) moment connection and tested several full-scale models (Richard et al 1997). This connection is referred to hereafter as a bolted-web, welded-flange with adequate ductility (BWWF-AD) and is conceptually illustrated in figure 3. As illustrated, top and bottom slots are cut in the beam web at the toe of the beam flange fillet from the end of the beam to shop-drilled slot termination holes. These slots play a pivotal role in the performance of BWWF-AD connections. The slot length depends on the nominal beam flange width, flange thickness, steel grade (yield strength), and nominal beam depth. A detailed design method and rationale for SSDA SlottedWeb ${ }^{\mathrm{TM}}$ moment connection including the design of shear plate can be found in SSDA Beam Slot Connection Manual (SSDA 1999, 2001).

SSDA test results and analytical studies showed substantial increase in the connection's strength and ductility, among other beneficial effects in comparison with BWWF connections (SSDA 2001). These tests met the plastic rotation criterion of 0.030 radian as required in the AISC Seismic Provisions for Structural Steel Buildings, dated April 15, 1997. These tests also met the required SAC (a joint venture of the Structural Engineers Association of California, the Applied Technology Council (ATC), and the Consortium of Universities for Research in Earthquake Engineering) and FEMA (Federal Emergency Management Agency) 
criterion of 0.040 radian of drift angle capacity for Special Moment Frames (SSDA 2001). ATC-24 protocol tests indicate that these connections develop full plastic moment capacity of the beam and do not reduce the elastic stiffness of the beam. They also developed stable hysteretic loops during testing. BWWF-AD connections are essentially partially restrained (PR) connections.

The authors were given access to some of the actual SSDA test results. Using the four parameters Richard model, represented by (9), the authors first proposed a mathematical model to represent moment-relative rotation $(M-\theta)$ curves for BWWF-AD connections (Mehrabian 2002). The model can generate $M-\theta$ curves for other beam-column assemblies not tested by SSDA. The details of the procedure cannot be discussed here but the four parameters can be estimated for any connection assembly as follows.

\subsection{Estimation of $K, K_{p}, M_{0}$, and $N$ parameters}

$K$ parameter can be shown to be (Mehrabian 2002):

$$
K=10,000 M_{p, b},
$$

where $M_{p, b}$ is the plastic moment capacity of the beam and can be as calculated as $Z \times F_{y}$, where $Z$ is the plastic section modulus of the beam and $F_{y}$ is the yield strength of steel. In calculating the plastic moment capacity of a beam, the yield strength of steel is considered to be 1.2 times the nominal yield strength, as suggested in FEMA-350 (2000). Since the size of the beam and grade of steel are known a priori, $M_{p, b}$ can be calculated in advance, and thus, the $K$ parameter can be estimated for any BWWF-AD connection.

Mehrabian (2002) showed that the other three parameters can be estimated as:

$$
K_{p}=4 \cdot 52 \mathrm{E}+05, M_{0}=M_{p, b}-115,050 \mathrm{kN}-\mathrm{cm} \text {, and } N=1 \cdot 0 .
$$

After the loading $M-\theta$ curve for a BWWF-AD connection is developed, the unloading and reloading behaviour can be generated as discussed in the previous section.

The behaviour of a flexible steel frame in the presence of FR connections, modelling them realistically as PR or BWWF (pre-Northridge) connections, and in the presence of improved BWWF-AD (post-Northridge) connections will be of considerable interest to the profession (Mehrabian et al 2005). Of course, the information on the reliability of the three systems can be used for comparison purposes and the unified hybrid approach presented next can be used for this purpose (Huh \& Haldar 2002).

\section{Time domain seismic reliability of real nonlinear structures using the hybrid approach}

Before presenting the hybrid approach, it is necessary to briefly discuss why the welldeveloped random vibration approach may not be appropriate for the problem under consideration. In the classical random vibration approach, the uncertainty in the dynamic loading is emphasized; the uncertainty in resistance-related and other load-related variables (dead and live loads) may not be incorporated appropriately, the presence of nonlinearity may need to be addressed indirectly, the reliability evaluation of real structures consisting of large numbers of dynamic degrees of freedoms may not be practical, and most importantly, the dynamic loadings including seismic loading cannot be applied in the time domain (Kanegaonkar \& Haldar 1987). Other alternatives need to be developed. In a typical nonlinear dynamic problem, the 
limit states are expected to be implicit and are also functions of time. Thus, the SFEM-based nonlinear algorithm for static problems developed by the first author and his team is not expected to be efficient in calculating the reliability. As discussed earlier, when the limit states are implicit, besides the SFEM-based approach, the two other alternatives for the reliability evaluations are the simulation and the response surface method (RSM). The simulation could be impractical for many applications. By the process of elimination, RSM is the only choice. However, if the region where the response surface needs to be generated is unknown, basic RSM is not expected to produce accurate and efficient results. For most practical problems, the failure region is unknown and the applicability of the RSM is expected to be a matter of chance. Some form of a hybrid alternative may be the only option.

\subsection{The hybrid approach}

The authors propose a hybrid method by combining the SFEM and the RSM approaches. In the SFEM approach, FORM is used to calculate the reliability index, the coordinates of the checking point or the most probable failure point, and the corresponding sensitivity index. Thus, as the iteration process continues, using the information on the sensitivity index, some of the less sensitive variables can be considered as deterministic, reducing the overall size of the problem. Then, using the information of the most probable failure point, the response surface can be generated around it. In the context of the RSM, it is known as the centre point. This gives the information on the probable failure region where the response surface needs to be generated. Basic RSM generally does not use information on distribution of the random variables even when it is available. However, when it is combined with the SFEM, it incorporates the information on distribution, thus improving the state of the art of the basic RSM significantly. The efficiency in generating the response surface is also of major concern. Since the proposed hybrid method is iterative in nature, its efficiency can be improved significantly by using a very efficient but less accurate RSM scheme in the intermediate iterations and a less efficient but very accurate scheme in the final iteration. The concept just discussed is expected to be accurate and efficient, improve or advance some of the concepts currently used in SFEM and RSM, and have the potential to improve the state-of-the-art of the reliability evaluation of real nonlinear dynamic systems in the time domain. The essential features of this novel approach are discussed next.

The major purpose of using RSM is to generate an approximate explicit expression for a performance or limit state function (Rajashekhar \& Ellingwood 1993; Huh \& Haldar 2001). At least a second-order polynomial is necessary for the nonlinear dynamic problem under consideration. The following two types of second-order polynomial are considered:

$$
\begin{aligned}
& \hat{g}(\mathbf{X})=b_{0}+\sum_{i=1}^{k} b_{i} X_{i}+\sum_{i=1}^{k} b_{i i} X_{i}^{2}, \\
& \hat{g}(\mathbf{X})=b_{0}+\sum_{i=1}^{k} b_{i} X_{i}+\sum_{i=1}^{k} b_{i i} X_{i}^{2}+\sum_{i=1}^{k-1} \sum_{j>i}^{k} b_{i j} X_{i} X_{j},
\end{aligned}
$$

where $X_{i}(i=1,2, \ldots, k)$ is the $i$ th random variable, and $b_{0}, b_{i}, b_{i i}$, and $b_{i j}$ are coefficients of the second-order polynomial. The polynomial can be fully defined using regression analysis or by solving a set of simultaneous equations using information on responses obtained at specific data points called sampling points. The selection of sampling points is a crucial factor in establishing the efficiency and accuracy of RSM. Saturated design (SD) and central 


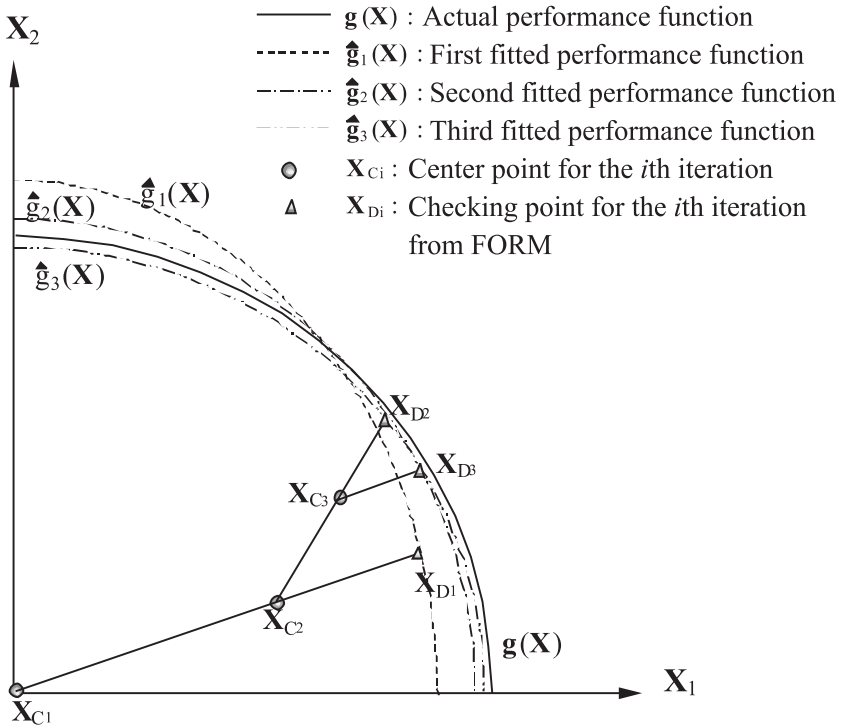

Figure 4. Iterative linear interpolation scheme (similar to Rajashekhar \& Ellingwood 1993).

composite design (CCD) are the two most promising techniques that can be used for this purpose. SD is less accurate but more efficient since it requires only as many sampling points as the total number of unknown coefficients to define the response surface. CCD is more accurate but less efficient since regression analysis needs to be carried out to evaluate the unknown coefficients in the response surface. By considering the two design methods and the form of the polynomial, the three promising response surface models suggested by Huh \& Haldar (2001) are: Model (1) - saturated design using a second-order polynomial without cross terms, model (2) - saturated design using a full second-order polynomial, and model (3) - CCD using a full second-order polynomial. They also suggest two promising schemes to improve the computational efficiency without compromising the accuracy. They are: Scheme 1 - SD using a second-order polynomial without cross terms [model (1)] for the intermediate iterations and saturated design using a full second-order polynomial for [model (2)] the final iteration, and scheme $2-\mathrm{SD}$ using a second-order polynomial without cross terms [model (1)] for the intermediate iterations and CCD using a full second-order polynomial [model (3)] for the final iteration. Both schemes are considered here.

Since the proposed algorithm is iterative, it is necessary to improve on the selection of the location of the centre point around which the sampling points are generated in the subsequent iterations. Bucher \& Bourgund (1990) suggested an iterative linear interpolation scheme as shown in figure 4 , which is also used in this study. It can be mathematically represented as:

$$
\begin{aligned}
& \mathbf{x}_{C_{2}}=\mathbf{x}_{C_{1}}+\left(\mathbf{x}_{D_{1}}-\mathbf{x}_{C_{1}}\right)\left\{g\left(\mathbf{x}_{C_{1}}\right) /\left[g\left(\mathbf{x}_{C_{1}}\right)-g\left(\mathbf{x}_{D_{1}}\right)\right]\right\} \text { if } g\left(\mathbf{x}_{D_{1}}\right) \geq g\left(\mathbf{x}_{C_{1}}\right), \\
& \mathbf{x}_{C_{2}}=\mathbf{x}_{D_{1}}+\left(\mathbf{x}_{C_{1}}-\mathbf{x}_{D_{1}}\right)\left\{g\left(\mathbf{x}_{D_{1}}\right) /\left[g\left(\mathbf{x}_{D_{1}}\right)-g\left(\mathbf{x}_{C_{1}}\right)\right]\right\} \text { if } g\left(\mathbf{x}_{D_{1}}\right)<g\left(\mathbf{x}_{C_{1}}\right),
\end{aligned}
$$

where $\mathbf{x}_{C_{1}}$ and $\mathbf{x}_{D_{1}}$ are the coordinates of the centre point and the checking point for the first iteration, and $g\left(\mathbf{x}_{C_{1}}\right)$ and $g\left(\mathbf{x}_{D_{1}}\right)$ are the actual responses of the limit state function estimated from the dynamic FEM analysis at $\mathbf{x}_{C_{1}}$ and $\mathbf{x}_{D_{1}}$ respectively. The point $\mathbf{x}_{C_{2}}$ can be used as a new centre point for the next iteration. This iteration scheme needs to be continued until a preselected convergence criterion is satisfied. The convergence criterion of $\left(\mathbf{x}_{C_{i+1}}-\mathbf{x}_{C_{i}}\right) / \mathbf{x}_{C_{i}} \leq$ $|0 \cdot 05|$ is used in the numerical examples of this study. 


\subsection{Solution strategy}

The algorithm just discussed appears to be simple but, in reality, is difficult. To implement it, the following steps can be undertaken.

Step 1: Develop the finite element representation of the structure. Decide if the connections are to be modelled as FR or PR type. Model the concrete shear wall and its property. The presence of concrete shear wall is discussed later.

Step 2: Identify uncertainties in all the variables in the formulation, as are widely available in the literature, or refer to Haldar \& Mahadevan (2000a).

Step 3: Select the earthquake time history of interest and its peak acceleration to consider uncertainty in the magnitude. A suite of acceleration time histories normalized to the same peak acceleration can be used for this purpose.

Step 4: Select the initial centre point to start the iteration at the mean values of all the random variables.

Step 5: Select a type of polynomial to represent the response surface.

Step 6: Analyse the structure deterministically at all the design points according to the model selected in step 5 using the nonlinear finite element algorithm.

Step 7: Generate the performance function by evaluating the coefficients in (16) and (17).

Step 8: Using the performance function thus generated, estimate the reliability index and the coordinates of the corresponding checking point using FORM.

Step 9: Using the information on the sensitivity indexes obtained in step 8, consider less sensitive random variables to be deterministic at their mean values.

Step 10: Find the coordinates of the new centre point to be used for the next iteration using the linear interpolation scheme given by (18) or (19).

Step 11: Repeat steps 5 to 10 until the coordinates of the centre point of all random variables converge to a pre-selected tolerance criterion. This completes the first $(n-1)$ iterations.

Step 12: Select a type of polynomial and corresponding experimental design model considering the desired accuracy in the final iteration.

Step 13: Construct the final response surface.

Step 14: Calculate the reliability index and the corresponding probability of failure.

\section{Example of steel frame with FR, BWWF, and BWWF-AD connections}

The hybrid method just presented is elaborated further with help of the following example. A two-storey steel frame, shown in figure 5, is considered for this illustrative example, with three connection assemblies. This was tested in the laboratory by SSDA. In all cases, the 


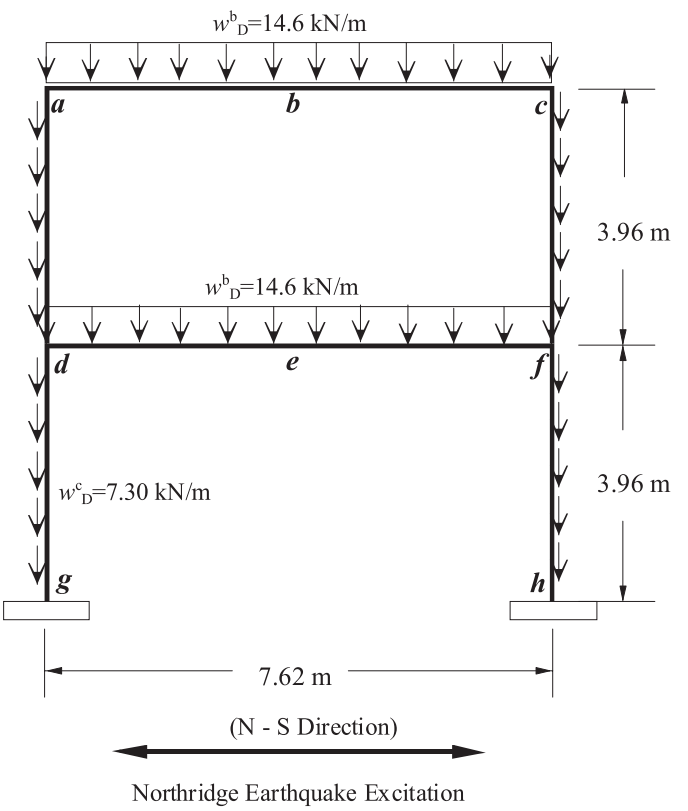

Figure 5. Two-storey steel frame structure.

column size was $W 14 \times 257$ but the beams were of sizes $W 24 \times 68, W 30 \times 116$, and $W 33 \times 118$, indicating different amounts of flexibility in the connections. They are denoted hereafter as assembly A, B, and C respectively. All columns and beams are made of A36 steel. In addition to their self-weight, dead loads of $14.6 \mathrm{kN} / \mathrm{m}$ and $7.30 \mathrm{kN} / \mathrm{m}$ are assumed to act on the beams and columns respectively. As mentioned earlier, the connections are routinely assumed to be FR type. If they are realistically considered to be PR type, Richard's four parameters are estimated by using a computer program PRCONN (Richard 1993). The parameters are summarized in table 1. If they are made of BWWF-AD improved post-Northridge PR connections, Richard's four parameters are estimated by using the procedure discussed earlier. Their values are also summarized in table 1 . The $M-\theta$ curves for these connections assuming they are BWWF and BWWF-AD types PR connections are plotted in figure 6. The figure clearly indicates the improved behaviour of the BWWF-AD connections.

Table 1. Parameters of Richard's equation for $M-\theta$ curves.

\begin{tabular}{|c|c|c|c|c|c|c|c|}
\hline \multirow{2}{*}{$\begin{array}{l}\text { Connection } \\
\text { type }\end{array}$} & \multicolumn{3}{|c|}{ Connection assembly } & \multicolumn{4}{|c|}{ Connection parameters } \\
\hline & ID. & Beam & Column & $K^{1}$ & $K_{p}^{1}$ & $M_{0}^{2}$ & $N$ \\
\hline \multirow[t]{3}{*}{ BWWF } & A & $W 24 \times 68$ & $W 14 \times 257$ & $2 \cdot 51 \mathrm{E}+07$ & $5 \cdot 56 \mathrm{E}+05$ & $4 \cdot 16 \mathrm{E}+04$ & $1 \cdot 1$ \\
\hline & B & $W 30 \times 116$ & $W 14 \times 257$ & $3 \cdot 95 E+07$ & $9 \cdot 19 \mathrm{E}+05$ & $5 \cdot 65 \mathrm{E}+04$ & $1 \cdot 1$ \\
\hline & $\mathrm{C}$ & $W 33 \times 118$ & $W 14 \times 257$ & $5 \cdot 08 \mathrm{E}+07$ & $1 \cdot 14 \mathrm{E}+05$ & $6 \cdot 79 \mathrm{E}+04$ & $1 \cdot 1$ \\
\hline \multirow[t]{3}{*}{ BWWF-AD } & A & $W 24 \times 68$ & $W 14 \times 257$ & $1.00 \mathrm{E}+09$ & $4 \cdot 52 \mathrm{E}+05$ & $9 \cdot 64 \mathrm{E}+04$ & 1.0 \\
\hline & B & $W 30 \times 116$ & $W 14 \times 257$ & $2 \cdot 14 \mathrm{E}+09$ & $4 \cdot 52 \mathrm{E}+05$ & $2 \cdot 21 E+05$ & 1.0 \\
\hline & $\mathrm{C}$ & $W 33 \times 118$ & $W 14 \times 257$ & $2 \cdot 34 \mathrm{E}+09$ & $4 \cdot 52 \mathrm{E}+05$ & $2 \cdot 44 \mathrm{E}+05$ & $1 \cdot 0$ \\
\hline
\end{tabular}

Note: ${ }^{1} \mathrm{kN} \cdot \mathrm{cm} / \mathrm{rad},{ }^{2} \mathrm{kN} \cdot \mathrm{cm}$ 


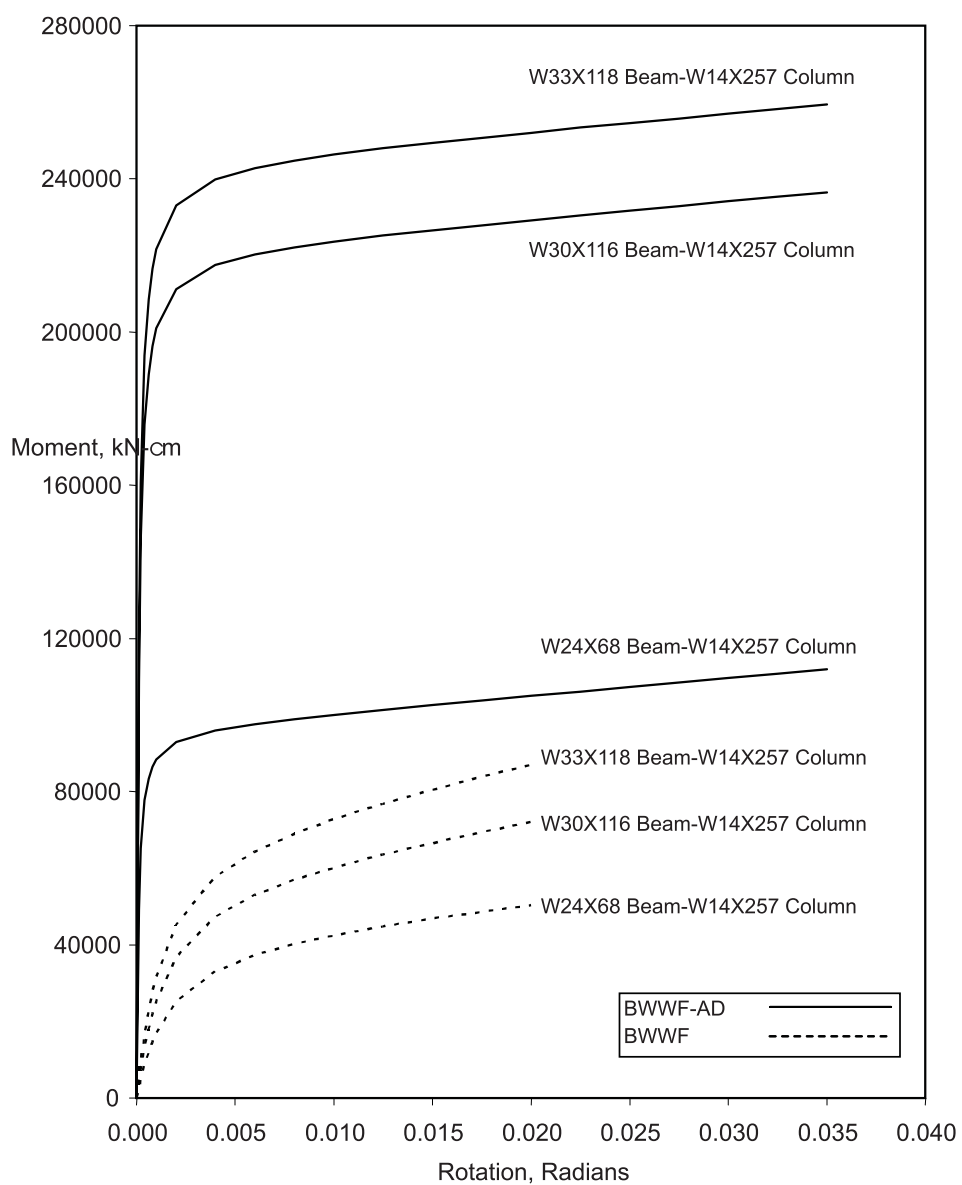

Figure 6. Moment-rotation curves for BWWF and BWWF-AD connections.

These frames are then excited for 15 seconds by the actual acceleration time history recorded at Canoga Park, California, during the Northridge earthquake of 1994 (N-S component) as shown in figure 7. The amplitude of the acceleration is scaled up with the help of a parameter $g_{e}$ as shown in table 2, to incorporate different sizes of the beams and to cause different amounts of distress in the members.

The members in the frame can develop strength failure or the frame may not be able to satisfy the serviceability requirements. Beam $e-f$ and column $f$ - $h$ in figure 5 are considered to be the weakest members in the frame and their reliabilities are to be estimated using the strength limit states given by (6) and (7). For the seismic loading, the lateral displacement at the top of the frame is considered to be the serviceability limit state in this example. The allowable displacement at the top of the frame, $\delta_{\text {allow }}$, is considered to be $h / 400$, where $h$ is the height of the frame. For this example, $\delta_{\text {allow }}$ is $1.98 \mathrm{~cm}$, and the corresponding serviceability limit state can be expressed as:

$$
g(\mathbf{x})=\delta_{\text {allow }}-y_{\max }(\mathbf{x})=1.98-y_{\max }(\mathbf{x}),
$$

where $y_{\max }(\mathbf{x})$ is the maximum lateral displacement at the top of the frame. 


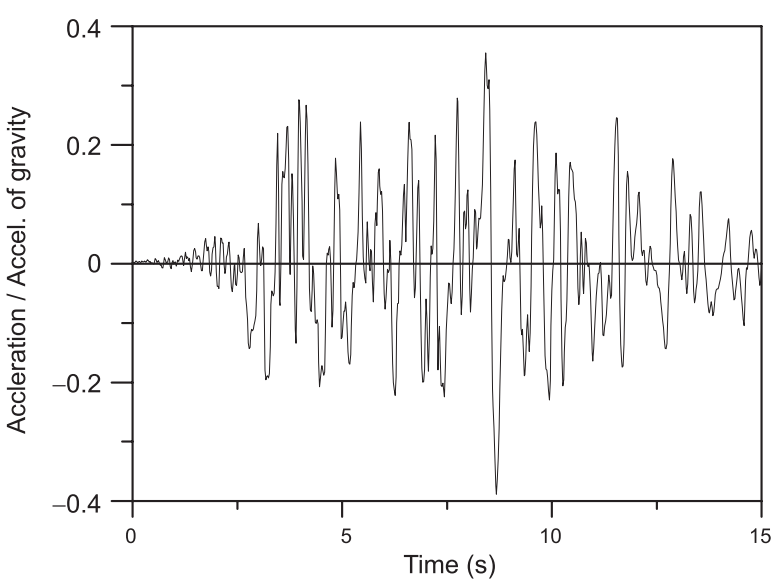

Figure 7. Northridge earthquake $(\mathrm{N}-\mathrm{S})$ time history.

The statistical descriptions of all the random variables present in the formulation are summarized in table 2. The information is collected from the available literature (Haldar \& Mahadevan 2000b). The damping, $\xi$, is considered to be $5 \%$ of the critical, commonly used in developing codified criteria in the U.S. All the parameters are assumed to be lognormal, except the amplitude parameter, $g_{e}$. It is considered to have extreme value type 1 distribution (Haldar \& Mahadevan 2000a).

First, all the connections in the frame are assumed to be pre-Northridge BWWF type, but they are assumed to be FR type in the analysis, following standard practice. They are then assumed to be PR-type BWWF connections in order to consider their realistic behaviour. Finally, they are considered to be PR-type BWWF-AD connections, representing post-Northridge connections. As mentioned earlier, PR-connections are modelled by the four-parameter Richard model. These parameters are also considered to be random variables, as shown in figure 8 . They are considered to be normal random variables. Their means are assumed to be the estimated values (Gao \& Haldar 1995b). The statistical descriptions of the four parameters for the three connection assemblies are given in table 3.

To implement the hybrid approach, the authors studied numerous schemes to generate the response surface. Considering both efficiency and accuracy, two schemes appear to be very promising. In both schemes, the intermediate iterations are conducted with the saturated design without cross terms. However, in scheme 1, the saturated design with full secondorder polynomial is used in the final iteration. In scheme 2, the CCD with full second-order polynomial is used in the final iteration.

The probabilities of failure of the frame in serviceability and strength are estimated using the hybrid approach for all three connection assemblies. However, results for assembly A only are summarized in table 4 . To verify the algorithm, the probabilities of failure of the frame using 50,000 Monte Carlo simulation (MCS) cycles are also estimated. The results are also summarized in table 4 .

Several important observations can be made from the results shown in table 4 . The proposed algorithm estimated the probabilities of failure for both limit states accurately. They are similar to the results obtained by MCS, verifying the algorithm. However, the ratio of total number of finite element method (FEM) analyses for MCS to that of the proposed algorithm ranges from 289 to 403 . This clearly indicates that the proposed algorithm accurately estimates the time domain reliability of complicated nonlinear structures by intelligently selecting a 


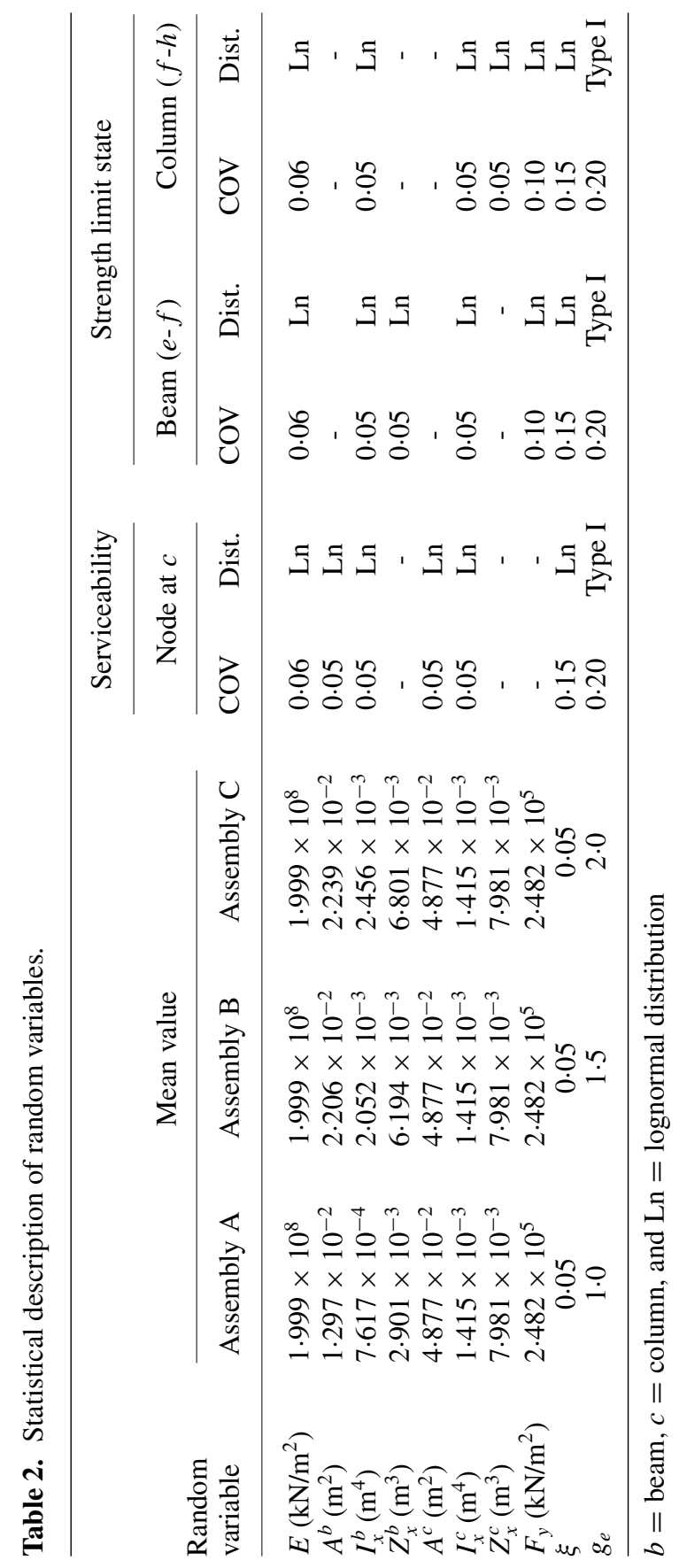




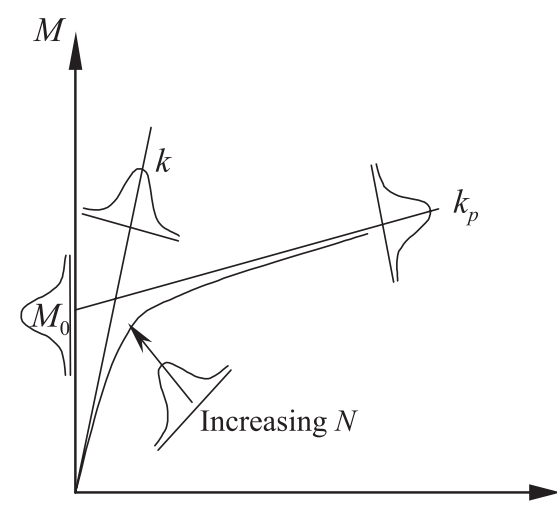

Figure 8. Uncertainty in the Richard parameters.

few hundred deterministic FEM analyses points instead of tens of thousands as required for the MCS. This computational efficiency without compromising on accuracy is one of the major desirable features of the proposed algorithm. Considering both accuracy and efficiency, scheme 1, i.e., the saturated design using a second-order polynomial without cross terms for the intermediate iterations and saturated design using a full second-order polynomial for the final iteration is advantageous, particularly when the number of random variables in the formulation is relatively large.

The probability of failure of the frame, as designed, is much higher in serviceability than in strength. When all the connections are considered to be FR-type, as commonly assumed, the probability of failure of the frame in strength is small. The frame will be acceptable following current design practice. However, it is very weak in serviceability and must be redesigned. This example clearly indicates the pitfalls of not checking serviceability requirements. As mentioned earlier, the connections are not really FR-type but PR-type and need to be modelled as BWWF-type, if we follow the pre-Northridge practices. If the connections are modelled appropriately, the probability of failure of the frame goes up significantly for both the serviceability and strength limit states. The most interesting observation is that the frame is now not acceptable in the strength limit state and needs to be redesigned for strength also.

Table 3. Statistical description of the four parameters in the Richard model.

\begin{tabular}{|c|c|c|c|c|c|c|}
\hline \multirow{2}{*}{$\begin{array}{l}\text { Connection } \\
\text { type }\end{array}$} & \multirow{2}{*}{$\begin{array}{l}\text { Random } \\
\text { variables }\end{array}$} & \multicolumn{3}{|c|}{ Mean value } & \multirow[b]{2}{*}{$\mathrm{COV}$} & \multirow[b]{2}{*}{ Distribution } \\
\hline & & Assembly A & Assembly B & Assembly C & & \\
\hline \multirow{4}{*}{ BWWF } & $k(\mathrm{kN} \cdot \mathrm{cm} / \mathrm{rad})$ & $2.51 \times 10^{7}$ & $3.95 \times 10^{7}$ & $5.08 \times 10^{7}$ & $0 \cdot 15$ & Normal \\
\hline & $k_{p}(\mathrm{kN} \cdot \mathrm{cm} / \mathrm{rad})$ & $5 \cdot 56 \times 10^{5}$ & $9.19 \times 10^{5}$ & $1.14 \times 10^{6}$ & $0 \cdot 15$ & Normal \\
\hline & $M_{0}(\mathrm{kN} \cdot \mathrm{cm})$ & $4.16 \times 10^{4}$ & $5.65 \times 10^{4}$ & $6.79 \times 10^{4}$ & $0 \cdot 15$ & Normal \\
\hline & $\mathrm{N}$ & $1 \cdot 1$ & $1 \cdot 1$ & $1 \cdot 1$ & 0.05 & Normal \\
\hline \multirow{4}{*}{ BWWF-AD } & $k(\mathrm{kN} \cdot \mathrm{cm} / \mathrm{rad})$ & $1.00 \times 10^{9}$ & $2 \cdot 14 \times 10^{9}$ & $2.34 \times 10^{9}$ & $0 \cdot 15$ & Normal \\
\hline & $k_{p}(\mathrm{kN} \cdot \mathrm{cm} / \mathrm{rad})$ & $4.52 \times 10^{5}$ & $4.52 \times 10^{5}$ & $4.52 \times 10^{5}$ & $0 \cdot 15$ & Normal \\
\hline & $M_{0}(\mathrm{kN} \cdot \mathrm{cm})$ & $9.64 \times 10^{4}$ & $2 \cdot 21 \times 10^{5}$ & $2.44 \times 10^{5}$ & $0 \cdot 15$ & Normal \\
\hline & $\mathrm{N}$ & $1 \cdot 0$ & $1 \cdot 0$ & 1.0 & 0.05 & Normal \\
\hline
\end{tabular}




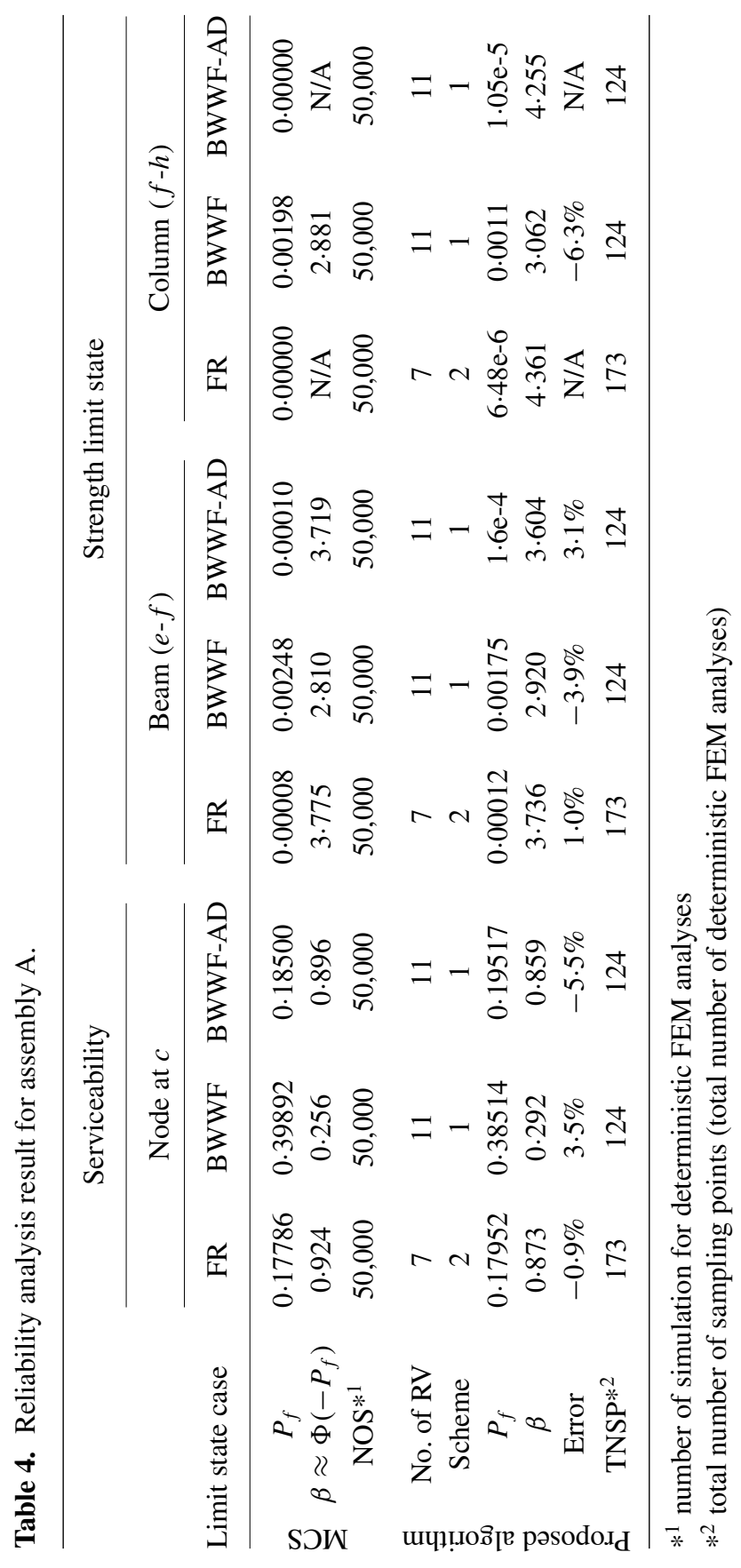


Table 5. Reliability indexes for the three connection assemblies.

\begin{tabular}{|c|c|c|c|c|c|c|c|c|c|}
\hline \multirow{3}{*}{$\begin{array}{l}\text { Assem- } \\
\text { bly }\end{array}$} & \multirow{2}{*}{\multicolumn{3}{|c|}{$\begin{array}{c}\text { Serviceability } \\
\text { Node at } c\end{array}$}} & \multicolumn{6}{|c|}{ Strength limit state } \\
\hline & & & & \multicolumn{3}{|c|}{ Beam $(e-f)$} & \multicolumn{3}{|c|}{ Column $(f-h)$} \\
\hline & FR & BWWF-AD & BWWF & FR & BWWF-AD & BWWF & FR & BWWF-AD & BWWF \\
\hline A & 0.873 & 0.859 & $0 \cdot 292$ & 3.736 & $3 \cdot 604$ & $2 \cdot 920$ & $4 \cdot 361$ & $4 \cdot 255$ & $3 \cdot 062$ \\
\hline $\mathrm{B}$ & 1.962 & $2 \cdot 001$ & -0.789 & 4.425 & 5.444 & 1.681 & 4.925 & $5 \cdot 941$ & 1.708 \\
\hline $\mathrm{C}$ & 0.932 & 0.932 & $-1 \cdot 035$ & 3.403 & $3 \cdot 432$ & 1.478 & 3.846 & 3.673 & 1.453 \\
\hline
\end{tabular}

The next option is to use post-Northridge connections in the frame. The probabilities of failure of the frame in strength and serviceability are evaluated using the proposed algorithm. The results are summarized in table 4. The frame is still unacceptable in serviceability; however, the probability of failure is similar to when connections are assumed to be FR-type. This validates the observation made by SSDA that the presence of BWWF-AD connections does not reduce the overall stiffness of the frame. The frame is now acceptable in strength also, even when the connections are assumed to be PR-type.

Reliability indexes for all three test assemblies are summarized in table 5. Again, the behaviours of the frame in the presence of FR and BWWF-AD connections are similar for both strength and serviceability limit states. However, in some cases, the frame fails to meet the strength requirements when modelled as pre-Northridge BWWF connections. The results clearly indicate the improved behaviour of the frame in the presence of postNorthridge connections. This study analytically confirms the desirable features of the BWWF$\mathrm{AD}$ connections observed during the laboratory investigations, particularly in seismically active regions.

\section{Steel frame with concrete shear walls}

The steel frame discussed in the previous section is unacceptable in serviceability, no matter how appropriately the connections are modelled. The lateral stiffness of the steel frame needs to be improved. Bracing systems or shear walls can be used for this purpose. Gao \& Haldar (1995b) used steel bracings, modelling them as truss members to improve the behaviour. Reinforced concrete (RC) shear walls are commonly used for this purpose. The use of RC shear walls increases the complexity in the problem due the use of two different materials. If the RC shear walls are placed properly, the structural elements may not fail in strength, but increase the lateral stiffness significantly. The consideration of the dual system consisting of a steel frame and RC shear walls increases the analytical complexity, introduces more variables in the formulation, and thus some additional sources of uncertainty. This is discussed next.

All the steel elements in the frame are modelled as beam-column elements, as discussed earlier. A four-node plane stress element is introduced for each shear wall in the frame. To derive an explicit expression of the stiffness matrix for the plate elements, the shape of the shear wall is restricted to be rectangular. Two displacement (horizontal and vertical) dynamic degrees of freedom are considered at each node point. The rotation of the combined system is expected to be very small. It is independently verified by using other computer programs. For the purpose of illustration, the rotation at a node is neglected. The stiffness of the RC shear 
walls needs to be added to the stiffness of the steel frame. The explicit form of a stiffness matrix of a 4-node plane stress element can be expressed as (Lee \& Haldar 2000b):

$$
K_{s h}=\frac{t}{4 \gamma} \mathbf{A}^{t} \mathbf{E A}+\frac{t}{12 \gamma} \mathbf{B}^{t} \mathbf{E B}+\frac{t \gamma}{12} \mathbf{C}^{t} \mathbf{E} \mathbf{C}
$$

where $t$ is thickness of the wall, $\gamma$ is the ratio of $b$ and $a$, i.e., $\gamma=b / a$, and $2 a$ and $2 b$ are long and short dimensions of the rectangular shear wall respectively. The matrixes $\mathbf{A}, \mathbf{B}, \mathbf{C}$, and $\mathbf{E}$ in (20) can be represented as:

$$
\begin{aligned}
& \mathbf{A}=\left[\begin{array}{cccccccc}
-\gamma & 0 & \gamma & 0 & \gamma & 0 & -\gamma & 0 \\
0 & -1 & 0 & -1 & 0 & 1 & 0 & 1 \\
-1 & -\gamma & -1 & \gamma & 1 & \gamma & 1 & -\gamma
\end{array}\right], \\
& \mathbf{B}=\left[\begin{array}{cccccccc}
0 & 0 & 0 & 0 & 0 & 0 & 0 & 0 \\
0 & 1 & 0 & -1 & 0 & 1 & 0 & -1 \\
1 & 0 & -1 & 0 & 1 & 0 & -1 & 0
\end{array}\right], \\
& \mathbf{C}=\left[\begin{array}{cccccccc}
1 & 0 & -1 & 0 & 1 & 0 & -1 & 0 \\
0 & 0 & 0 & 0 & 0 & 0 & 0 & 0 \\
0 & 1 & 0 & -1 & 0 & 1 & 0 & -1
\end{array}\right]
\end{aligned}
$$

and

$$
\mathbf{E}=\frac{E_{C}}{\left(1-v^{2}\right)}\left[\begin{array}{ccc}
1 & v & 0 \\
v & 1 & 0 \\
0 & 0 & (1-v) / 2
\end{array}\right] .
$$

where $E_{C}$ is modulus of elasticity and $v$ is Poisson's ratio of shear walls. The finite element representation of the $\mathrm{RC}$ shear walls is kept simple in order to minimize the number of basic random variables present in the formulation. More sophisticated methods can be attempted in future studies, if desired. Reliability evaluation procedures are emphasized in this paper.

$\mathrm{RC}$ shear walls are considered in this study. Thus, two additional parameters, namely, the modulus of elasticity and Poisson's ratio of concrete are necessary in the deterministic formulation, as can be seen in (25). Modelling of the stiffness of shear walls is not easy. The tensile strength of concrete is small compared to its compressive strength. Cracking may develop at a very early stage of loading. The behaviour of a $\mathrm{RC}$ shear wall is expected to be significantly different before and after cracking (Gupta \& Akbar 1984; Liauw \& Kwan 1985; Vecchio 1989; Lefas et al 1990; Inoue et al 1997). It is observed that degradation of the stiffness of the shear walls occurs after cracking and can be considered effectively by reducing the modulus of elasticity of the shear walls. Lefas et al (1990) report that the degradation of the stiffness after cracking could vary from $40 \%$ to $70 \%$ of the original stiffness depending on the amount of reinforcement and the intensity of axial loads. The same concept is used in this study. The shear wall is assumed to develop cracks when the tensile stress in concrete exceeds the prescribed value. The rupture strength of concrete, $f_{r}$, is assumed to be $f_{r}=7.5 \times \sqrt{f_{c}^{\prime}}$, where $f_{c}^{\prime}$ is the compressive strength of concrete.

\subsection{Example on reliability estimation of a steel frame reinforced with $R C$ shear walls}

A laterally weak frame, reinforced with RC shear walls, is considered next to show the application potential of the proposed method. The dual system is shown in figure 9. Although 


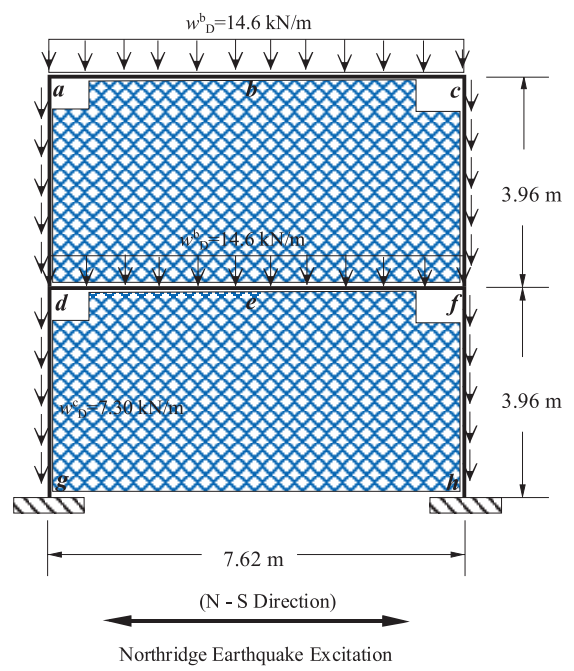

Figure 9. Two-storey steel frame with shear walls.

the physical thickness of the shear wall is considered to be $12.7 \mathrm{~cm}$, considering the presence of 5 similar frames in the structure and rigid behaviour of diaphragms, the effective thickness per frame is assumed to be $2.54 \mathrm{~cm}$ for this example. When the tensile stress of each shear wall exceeds the prescribed tensile stress of concrete, the degradation of the shear wall stiffness is assumed to be reduced to $40 \%$ of the original stiffness.

The uncertainty in all the variables considered for the bare steel frame remains the same. However, two additional sources of uncertainty, namely in $E_{C}$ and $v$, need to be considered, as given in table 6 .

The frame is again excited for 15 seconds by the same Northridge earthquake of 1994 (N-S component) as shown in figure 7, as used in the previous case. The probabilities of failure for the combined system in presence of FR, BWWF-AD, and BWWF connections for the serviceability limit state are calculated using the proposed algorithm with scheme 1 . Due to the attachment with the RC shear walls, all the members will satisfy the strength requirements. The reliability indexes for the dual system are evaluated for the horizontal deflection at the top of the frame at point $c$ in figure 9 . The results are summarized in table 7 . The results indicate that the presence of shear walls significantly improves the serviceability behaviour of the steel frame, as expected. However, the amount of improvement in terms of probability of failure can be quantified using the proposed algorithm considering major sources of uncertainty.

Table 6. Statistical description of random variables in RC shear walls.

\begin{tabular}{lccccc}
\hline Item & Random variables & Mean value & COV & Distribution & Comment \\
\hline \multirow{2}{*}{ Shear wall } & $E_{C}\left(\mathrm{kN} / \mathrm{m}^{2}\right)$ & $2.140 \times 10^{7}$ & 0.18 & $\mathrm{Ln}$ & $f_{C}^{\prime}=2.068 \times 10^{4}$ \\
& $v$ & 0.17 & 0.10 & $\mathrm{Ln}$ & $\left(\mathrm{kN} / \mathrm{m}^{2}\right)$ \\
\hline
\end{tabular}


Table 7. Reliability indexes for the serviceability limit state of the steel frame with RC shear walls for connection assembly A.

\begin{tabular}{lccc}
\hline & \multicolumn{3}{c}{ Connection type } \\
\cline { 2 - 4 } & FR & BWWF-AD & BWWF \\
\hline Without shear walls & 0.873 & 0.859 & 0.292 \\
With shear walls & 3.615 & 3.552 & 3.246 \\
\hline
\end{tabular}

\section{Conclusions}

A novel reliability analysis technique is presented to evaluate the seismic reliability of nonlinear real structures in the time domain. The unique feature of the method is that the dynamic loadings including the seismic loading can be applied in time domain. It is essentially a nonlinear stochastic finite element logarithm combined with the response surface method (RSM). The proposed method advances the state of the art in the RSM by incorporating information of the distribution of the random variables and generating the response surface around the most probable failure point. The method provides an alternative to the classical random vibration method. The method is found to be very efficient and accurate. It is verified using the Monte Carlo simulation technique. All major sources of nonlinearity and uncertainty can be explicitly incorporated in the formulation. In addition to geometric and material nonlinearities, the flexibility of connections in steel frames is addressed. The flexibility of the connections is represented by moment-relative rotation $(M-\theta)$ curves. Richard's fourparameter model is used for this purpose. After the Northridge earthquake of 1994, several improved steel connections were proposed and tested in the laboratory. Structural Sesimic Design Associates (SSDA) proposed a very unique proprietory slotted web beam-column connection and tested several full-scale models. The authors suggested $(M-\theta)$ curves for this type of connection using actual test data. Behaviours of steel frames assuming the connections are fully restrained, as routinely assumed in the profession, partially restrained consisting of pre-Northridge connections, and improved post-Northridge connections are evaluated and compared. Desirable features of the post-Northridge connections observed during the laboratory investigations are analytically confirmed using the proposed method. Laterally weak steel frames are then strengthened with reinforced concrete shear walls. The improved behaviour of the dual system is evaluated with the help of the proposed method. One of the major objections that the currently available reliability evaluation techniques are not adequate to evaluate risk of real complex structural systems, particularly when excited by short duration dynamic loadings including seismic loading, is thus properly addressed. The capabilities of the proposed method are demonstrated with the help of several realistic examples. The paper demonstrates the advanced nature of the reliability evaluation technique to estimate the risks of real complicated structural systems. No similar method can be found in the literature.

The work presented here was sponsored by the financial support of many organizations including the National Science Foundation and the American Institute of Steel Constructions 
Inc., over a period of time. The authors are thankful to other research team members for their contributions in developing the algorithm including, Professor S Mahadevan, Dr Y Zhou, Dr L Gao, Professor A S Reyes and Dr S Y Lee.

\section{References}

AISC 2001 Manual of steel construction: load and resistance factor design 3rd edn (Chicago: American Institute of Steel Construction)

Bucher C G, Bourgund U 1990 A fast and efficient response surface approach for structural reliability problems. Struct. Safety 7: 57-66

Colson A 1991 Theoretical modelling of semi-rigid connection behaviour. J. Construct. Steel Res. 19: 213-224

Engelhardt M D, Sabol T A 1995 Testing of welded steel moment connections in response to the Northridge earthquake. Progress Report to the AISC Advisory Subcommittee on Special Moment Resisting Frame Research, University of Texas at Austin

FEMA 2000 Recommended seismic design criteria for new steel moment-frame structures. Federal Emergency Management Agency (FEMA) Washington, DC 350-353 and 355A-F

Gao L, Haldar A 1995a Safety evaluation of frames with PR connections. J. Struct. Eng. ASCE 121: 1101-1109

Gao L, Haldar A 1995b Nonlinear seismic analysis of space structures with partially restrained connections. Microcomput. Civil Eng. 10: 27-37

Gupta A K, Akbar H 1984 Cracking in reinforced concrete analysis. J. Struct. Eng. ASCE 110: 17351746

Haldar A, Mahadevan S 2000a Probability, reliability and statistical methods in engineering design (New York: John Wiley \& Sons)

Haldar A, Mahadevan S 2000b Reliability assessment using stochastic finite element analysis (New York: John Wiley \& Sons)

Haldar A, Nee K-M 1989 Elasto-plastic large deformation analysis of PR steel frames for LRFD. Int. J. Comput. Struct. 34(5): 811-823

Haldar A, Zhou Y 1992 Reliability of geometrically nonlinear PR frames. J. Eng. Mech. ASCE 118: 2148-2155

Huh J, Haldar A 2001 Stochastic finite element-based seismic risk evaluation for nonlinear structures. J. Struct. Eng., ASCE 127: 323-329

Huh J, Haldar A 2002 Seismic reliability of nonlinear frames with PR connections using systematic RSM. Probab. Eng. Mech. 17: 177-190

Inoue N, Yang K, Shibata A 1997 Dynamic nonlinear analysis of reinforced concrete shear wall by finite element method with explicit analytical procedure. Earthquake Eng. Struct. Dyn. 26: 967-986

Kanegaonkar H B, Haldar A 1987 Nonlinear random vibrations of compliant offshore platforms. Int. Union of Theoretical and Applied Mechanics on Nonlinear Stochastic Dynamic Engineering Systems (eds) Ziegler, Schueller (Berlin, Heidelberg: Springer-Verlag) pp 351-360

Lee S Y, Haldar A 2003a Reliability analysis of frame and shear wall structural systems - static loading. J. Struct. Eng. Div. ASCE 129: 224-232

Lee S Y, Haldar A 2003b Reliability analysis of frame and shear wall structural systems - dynamic loading. J. Struct. Eng. Div. ASCE 129: 233-240

Lefas D, Kotsovos D, Ambraseys N 1990 Behaviour of reinforced concrete structural walls: strength, deformation characteristics, and failure mechanism. ACI Struct. J. 87: 23-31

Liauw T C, Kwan K H 1985 Static and cyclic behaviours of multistory infilled frames with different interface conditions. J. Sound Vibr. 99: 275-283

Mahadevan S, Haldar A 1991 Stochastic FEM-based validation of LRFD. J. Struct. Eng. Div., ASCE 117: 1393-1412 
Mehrabian A 2002 Seismic performance of steel frames with a "post-Northridge" connection. Ph. D. dissertation, Department of Civil Engineering and Engineering Mechanics, University of Arizona, Tucson. AZ

Mehrabian A, Haldar A, Reyes A S 2005 Seismic response analysis of steel frames with postNorthridge connection. Steel Composite Struct. 5: 271-287

Rajashekhar M R, Ellingwood B R 1993 A new look at the Response Surface approach for reliability analysis. Struct. Safety 12: 205-220

Reyes A S, Haldar A 2001 Energy dissipation at PR frames under seismic loading. J. Struct. Eng. Div., ASCE 127: 588-592

Richard R M 1993 PRCONN Manual. RMR Design Group, Tucson, AZ

Richard R M, Abbott B J 1975 Versatile elastic-plastic stress-strain formula. J. Eng. Mech. Div., ASCE 101: 511-515

Richard R M, Allen C J, Partridge J E 1997 Proprietary slotted beam connection designs. Modern Steel Construction, Chicago, IL, pp 28-33

Richard R M, Radau R E 1998 Force, stress and strain distribution in FR bolted welded connections. Proc. Structural Engineering Worldwide

SSDA 1999, 2001 SSDA beam slot connection manuals. Seismic Structural Design Associates, Inc., CA, USA

Vecchio F J 1989 Nonlinear finite element analysis of reinforced concrete membranes. ACI Struct. J. :26-35 